\title{
Necdin Downregulates Cdc2 Expression to Attenuate Neuronal Apoptosis
}

\author{
Mitsumasa Kurita, Takaaki Kuwajima, Isao Nishimura, and Kazuaki Yoshikawa \\ Laboratory of Regulation of Neuronal Development, Institute for Protein Research, Osaka University, Osaka 565-0871, Japan
}

The cell cycle-regulatory transcription factor E2F1 induces apoptosis of postmitotic neurons in developmental and pathological situations. E2F1 transcriptionally activates many proapoptotic genes including the cyclin-dependent protein kinase cell division cycle 2 (Cdc2). Necdin is a potent mitotic suppressor expressed predominantly in postmitotic neurons and interacts with E2F1 to suppress E2F1-mediated gene transcription. The necdin gene NDN is maternally imprinted and expressed only from the paternal allele. Deletion of the paternal NDN is implicated in the pathogenesis of Prader-Willi syndrome, a genomic imprinting-associated neurodevelopmental disorder. Here, we show that paternally expressed necdin represses E2F1-dependent $c d c 2$ gene transcription and attenuates apoptosis of postmitotic neurons. Necdin was abundantly expressed in differentiated cerebellar granule neurons (CGNs). Neuronal activity deprivation elevated the expression of both $\mathrm{E} 2 \mathrm{~F} 1$ and $\mathrm{Cdc} 2$ in primary CGNs prepared from mice at postnatal day 6, whereas the necdin levels remained unchanged. In chromatin immunoprecipitation analysis, endogenous necdin was associated with the $c d c 2$ promoter containing an E2F-binding site in activity-deprived CGNs. After activity deprivation, CGNs underwent apoptosis, which was augmented in those prepared from mice defective in the paternal Ndn allele $\left(\mathrm{Ndn}^{+\mathrm{m} /-\mathrm{p}}\right)$. The levels of $c d c 2 \mathrm{mRNA}$, protein, and kinase activity were significantly higher in $\mathrm{Ndn}{ }^{+\mathrm{m} /-\mathrm{p}}$ CGNs than in wild-type CGNs under activity-deprived conditions. Furthermore, the populations of Cdc2-immunoreactive and apoptotic cells were increased in the cerebellum in vivo of $\mathrm{Ndn}^{+\mathrm{m} /-\mathrm{p}}$ mice. These results suggest that endogenous necdin attenuates neuronal apoptosis by suppressing the E2F1-Cdc2 system.

Key words: necdin; E2F1; Cdc2; cerebellum; apoptosis; Prader-Willi syndrome

\section{Introduction}

E2 promoter-binding factor (E2F) transcription factors play key roles in cell proliferation (Nevins, 2001). These transcription factors contribute to the proliferation of neural stem cells and death of postmitotic neurons (Yoshikawa, 2000; Greene et al., 2004). The proapoptotic E2F member E2F1 is controlled by the retinoblastoma $(\mathrm{Rb})$ protein, which is normally hypophosphorylated in quiescent cells and hyperphosphorylated during cell cycle progression to release active E2F1 (Weinberg, 1995; Nevins, 2001). During neurogenesis, $\mathrm{Rb}$ is involved in both terminal mitosis and neuronal differentiation (Ferguson and Slack, 2001). Rb deficiency causes deregulation of E2F1 and leads to neuronal apoptosis (Jacks et al., 1992; Lee et al., 1994). Apoptotic stimuli induce $\mathrm{Rb}$ phosphorylation through activation of cyclin-dependent kinases to activate E2F1 in neurons (Park et al., 2000; Hou et al., 2002). In addition, forced expression of E2F1 in postmitotic neurons using viral vectors induces apoptosis (Azuma-Hara et al., 1999; Hou et al., 2000; O’Hare et al., 2000). These findings sug-

\footnotetext{
Received May 6, 2006; revised 0ct. 6, 2006; accepted 0ct. 11, 2006.

This work was supported by grants-in-aid from the Japan Society for the Promotion of Science and from the Ministry of Education, Culture, Sports, Science and Technology of Japan (the National Project on Protein Structure and Functional Analysis).

Correspondence should be addressed to Dr. Kazuaki Yoshikawa, Institute for Protein Research, Osaka University,

3-2 Yamadaoka, Suita, 0saka 565-0871, Japan. E-mail: yoshikaw@protein.osaka-u.ac.jp.

DOI:10.1523/JNEUROSCI.3002-06.2006

Copyright $\odot 2006$ Society for Neuroscience ～0270-6474/06/2612003-11\$15.00/0
}

gest that the regulation of E2F1 activity is crucial for the control of neuronal apoptosis.

Necdin is a potent mitotic suppressor that is expressed predominantly in postmitotic neurons (Maruyama et al., 1991; Aizawa et al., 1992; Hayashi et al., 1995; Uetsuki et al., 1996). Necdin, like Rb, targets E2F1 and represses E2F1-dependent transcription in osteosarcoma cells (Taniura et al., 1998; Kuwako et al., 2004). Ectopic expression of necdin inhibits E2F1-induced apoptosis of differentiated neuroblastoma cells (Kobayashi et al., 2002; Kuwako et al., 2004). However, it remains unclear whether endogenous necdin inhibits E2F1-dependent transcription and apoptosis in postmitotic neurons. The human necdin gene NDN is located on chromosome 15q11.2-q12 (Nakada et al., 1998), a region responsible for the pathogenesis of the genomic imprinting-associated neurodevelopmental disease Prader-Willi syndrome (PWS). In fact, NDN is maternally imprinted, transcribed only from the paternal allele, and not expressed in PWS (Jay et al., 1997; MacDonald and Wevrick, 1997; Sutcliffe et al., 1997). Mutant mice defective in the paternal necdin allele display neuronal abnormalities reminiscent of PWS (Gerard et al., 1999; Muscatelli et al., 2000; Ren et al., 2003; Lee et al., 2005; Pagliardini et al., 2005). We found that necdin deficiency enhances apoptosis in nerve growth factor (NGF)-dependent sensory neurons (Takazaki et al., 2002; Kuwako et al., 2005). These findings led us to investigate the significance of interactions between endogenous necdin and E2F1 in postmitotic neurons.

Cerebellar granule neurons (CGNs), which are often used as a 
model for activity deprivation-induced apoptosis (D'Mello et al., 1993), accumulate E2F1 and cell division cycle 2 (Cdc2) in response to $\mathrm{KCl}$ withdrawal (O'Hare et al., 2000; Konishi et al., 2002; Konishi and Bonni, 2003). In the present study, we use primary CGNs prepared from necdin-deficient mice to demonstrate the necdin-mediated suppression of E2F1-dependent $c d c 2$ expression. Furthermore, we show that necdin deficiency enhances Cdc2-mediated apoptosis in activity-deprived CGNs in vitro and in the cerebellum in vivo. Our data indicate that necdin is physiologically involved in neuronal survival by suppressing the E2F1-Cdc2 pathway, which is activated in various neuropathological conditions.

\section{Materials and Methods}

Immunostaining. Frozen sections of the cerebellum of ICR mice (SLC, Shizuoka, Japan) at postnatal day 6 (P6) and cultured CGNs were prepared for staining as described previously (Nishimura et al., 1998; Nishimura et al., 2002). Fixed tissues and cells were incubated with primary antibodies against necdin (NC243, 1:500) (Niinobe et al., 2000), Ki67 (1:200; BD Biosciences, San Diego, CA), $\beta$ III-tubulin (1:1000; Promega, Madison, WI), microtubule-associated protein (MAP2) (1:1000; gift from Dr. M. Niinobe, Osaka University, Osaka, Japan), and NeuN (A60, 1:300; Chemicon, Temecula, CA) in PBS containing 0.05\% Tween 20 and $2 \%$ normal goat serum at $4^{\circ} \mathrm{C}$ for $12 \mathrm{~h}$. The samples were then incubated at room temperature for $2 \mathrm{~h}$ with anti-rabbit and anti-mouse IgGs conjugated with fluorescein isothiocyanate (Cappel, Durham, NC) and rhodamine B (Cappel). Chromosomal DNA was stained with $5 \mu \mathrm{M}$ Hoechst 33342 (Sigma, St. Louis, MO). For Cdc2 immunohistochemistry, paraffin-embedded 8 - $\mu \mathrm{m}$-thick sections were incubated with antibodies against Cdc2 [p34 (17), 1:200; Santa Cruz Biotechnology, Santa Cruz, CA] and activated caspase-3 (ACP3, 1:1000) (Uetsuki et al., 1999; Nishimura et al., 2002) in PBS containing $0.05 \%$ Triton X-100 and 2\% normal goat serum at room temperature for $12 \mathrm{~h}$, and with secondary antibodies as above. The Cdc2-immunoreactive cells in folium III, which was readily distinguishable from other cerebellar folia, were counted. Fluorescent images were observed with a fluorescence microscope (BX50-34-FLAD1; Olympus, Tokyo, Japan) with a CCD camera (M-3204C; Olympus) and processed using Adobe Photoshop software.

CGN cultures. Primary cultures of CGNs were prepared from P6 ICR mice and cultured as described previously (Ichikawa et al., 1998). Briefly, the cerebellum was cut into small pieces; incubated with $1 \mathrm{ml}$ of $\mathrm{Ca}^{2+}$, $\mathrm{Mg}^{2+}$-free, glucose-supplemented HBSS containing $0.125 \%$ trypsin for $10 \mathrm{~min}$ at $37^{\circ} \mathrm{C}$; and digested with $0.005 \%$ DNase I (Sigma) for $5 \mathrm{~min}$ at $37^{\circ} \mathrm{C}$. After centrifugation, the cell pellet was suspended in DMEM supplemented with $10 \%$ fetal calf serum (FCS) and triturated with a Pasteur pipette. Dispersed cells were suspended in DMEM supplemented with $10 \%$ FCS and plated at a density of $5 \times 10^{5} \mathrm{cells} / \mathrm{cm}^{2}$ in culture dishes precoated with poly-DL-ornithine. The cells were cultured at $25 \mathrm{mM} \mathrm{KCl}$ and $25 \mathrm{~mm}$ glucose in DMEM supplemented with $10 \% \mathrm{FCS}$ at $37^{\circ} \mathrm{C}$ in a humidified 5\% $\mathrm{CO}_{2}$ atmosphere. Primary CGNs were treated $24 \mathrm{~h}$ later with $5 \mu \mathrm{g} / \mathrm{ml}$ cytosine arabinoside (Sigma) to suppress the proliferation of non-neuronal cells (Konishi and Bonni, 2003) and maintained for an additional $24 \mathrm{~h}$ before $\mathrm{KCl}$ withdrawal, unless described otherwise.

Cell death analyses. CGNs were incubated in DMEM supplemented with $10 \% \mathrm{FCS}, 5 \mathrm{~mm} \mathrm{KCl}$, and $25 \mathrm{~mm}$ glucose; fixed with $4 \%$ formaldehyde in PBS, $\mathrm{pH} 7.4$, at $4^{\circ} \mathrm{C}$ for $20 \mathrm{~min}$; and permeabilized with methanol/acetone $(1: 1)$ at $-20^{\circ} \mathrm{C}$ for $20 \mathrm{~min}$. For nuclear DNA staining, CGNs were cultured in the presence of $10 \mu \mathrm{M}$ Hoechst 33342 (Sigma) for $5 \mathrm{~min}$ before the fixation, and CGNs carrying condensed or fragmented nuclei were judged as apoptotic cells. For terminal deoxynucleotidyltransferasemediated dUTP nick-end labeling (TUNEL), fixed cells were labeled using an In Situ Cell Death Detection kit (Roche, Basel, Switzerland). After TUNEL staining, the cells were immunostained with anti-MAP2 antibody, and TUNEL-positive cells among MAP2-positive cells were counted. For activated caspase-3 immunostaining, fixed cells were double stained with ACP3 and the antibody against $\beta$ III-tubulin (Nishimura et al., 2002). For detection of TUNEL-positive cells in the cerebellum in vivo, frozen 14- $\mu \mathrm{m}$-thick cerebellum sections were prepared from P6 mice, and TUNEL reactivity was detected by the avidin-biotin peroxidase complex method using the Vectastain ABC kit (Vector Laboratories, Burlingame, CA) (Nishimura et al., 1998). TUNEL-positive cells in the cerebellum of littermates were counted and presented as the number per square millimeter.

Immunoblotting. CGNs were homogenized with a lysis buffer containing $50 \mathrm{~mm}$ Tris- $\mathrm{HCl}, \mathrm{pH} 8.0,150 \mathrm{~mm} \mathrm{NaCl}, 1 \%$ Nonidet P-40, $1 \mathrm{~mm}$ EDTA, and the Complete protease inhibitor mixture (Roche) and centrifuged to obtain the supernatant. Cytoplasmic and nuclear soluble fractions were prepared from CGNs as described previously (Taniguchi et al., 2000). Embryonal carcinoma P19 cells were induced to differentiate into neurons as described previously (McBurney et al., 1988). The equal amounts of proteins $(25-30 \mu \mathrm{g})$ were separated by $10 \%$ SDS-PAGE, blotted onto Immobilon membrane (Millipore, Billerica, MA), and incubated with antibodies against necdin (NC243, 1:1000), $\beta$-tubulin (1: 1000; MA Biomedicals, Irvine, CA), and phospho-specific Rb (Ser795, 1:300; New England Biolabs, Beverly, MA). The following antibodies against cell cycle-related proteins were purchased from Santa Cruz Biotechnology: E2F1 (C-20, 1:300), E2F4 (C-108, 1:300), cyclin B1 (GNS1, 1:300), cyclin A (C-19, 1:300), Cdc2 [p34 (17), 1:300], proliferating cell nuclear antigen (PCNA) (PC10, 1:500), HDAC-1 (C-19, 1:300), Rb (C15, 1:300), p107 (C-18, 1:300), and p130 (C-20, 1:300). After incubation with peroxidase-conjugated anti-rabbit IgG (Cappel), anti-mouse IgG (Cappel), and anti-goat IgG (Santa Cruz Biotechnology), proteins were visualized with chemiluminescence reagents (Chemiluminescence Reagent Plus; PerkinElmer, Boston, MA). The protein concentration was determined by the Bradford method (Bio-Rad, Hercules, CA). E2F1 and $\mathrm{Cdc} 2$ levels relative to tubulin levels were quantified with an image analyzer (LAS-1000 Plus; Fuji Film, Tokyo, Japan).

Reporter assay. P19 cells were plated at a density of $2 \times 10^{5}$ cells in 35 $\mathrm{mm}$ dishes, cultured for $24 \mathrm{~h}$ in DMEM supplemented with 10\% FCS, and transfected with the luciferase reporter plasmid PGV-B (Toyo Ink, Tokyo, Japan) containing the mouse $c d c 2$ promoter $(-498$ to $+46 \mathrm{bp}$; $0.5 \mu \mathrm{g})$, pRc-E2F1 $(0.5 \mu \mathrm{g})$, and pRc-necdin $(0.5,1.0$, and $2.0 \mu \mathrm{g})$ by polycationic liposome-mediated DNA transfection using LipofectAMINE 2000 (Invitrogen, Carlsbad, CA). The total amount of plasmid DNA was adjusted to $4 \mu \mathrm{g}$ by adding empty pcDNA3.1 (Invitrogen). Transfected cells were incubated for $24 \mathrm{~h}$, and the luciferase activity was measured with a luminometer (Lumat LB9501; Berthold, Bad Wildbad, Germany) using a reagent kit (Toyo Ink). Transfection efficiency was normalized with coexpressed pRc-LacZ $(0.5 \mu \mathrm{g})$.

Chromatin immunoprecipitation. Chromatin immunoprecipitation (ChIP) analysis was performed as described previously (Luo et al., 1998). Briefly, formaldehyde cross-linked cell lysates $(0.5$ and $1 \mathrm{mg})$ were sonicated to generate an average DNA size of $\sim 500 \mathrm{bp}$ and were incubated at $4^{\circ} \mathrm{C}$ for $12 \mathrm{~h}$ with rabbit polyclonal antibodies against necdin (NC243), mouse E2F1 (MFE2F1) (Azuma-Hara et al., 1999), and preimmune IgG. The antibody-bound complexes were pelleted with protein-A Sepharose (Amersham Biosciences) at $4^{\circ} \mathrm{C}$ for $6 \mathrm{~h}$. The immunoprecipitated complexes were reverse-cross-linked by heating at $65^{\circ} \mathrm{C}$ for $12 \mathrm{~h}$. Input DNA and immunoprecipitated DNA were treated with proteinase K, precipitated with ethanol, and resuspended in sterile water. PCR was performed using template DNA (input DNA and immunoprecipitated DNA) and the following primers: $c d c 2$ promoter ( $155 \mathrm{bp}$; forward, $5^{\prime}$-acagagctcaagagtcagttggc- $3^{\prime}$; reverse, $5^{\prime}$-cgccaatccgattgcacgtaga- $\left.3^{\prime}\right), \beta$-actin promoter (105 bp; forward, 5'-gcttctttgcagctccttcgttg-3'; reverse, $5^{\prime}$ ctttgcacatgccggagccgttgt- $3^{\prime}$ ). For ChIP assay in transiently transfected P19 cells with a $c d c 2$ promoter luciferase vector, the following primers were used (318 bp; forward, 5' -acagagctcaagagtcagttggc- $3^{\prime}$; reverse, $5^{\prime}$ cggttccatcctctagaggatagaat- $\left.3^{\prime}\right)$. Signal intensities were quantified with NIH Image 1.63 software.

Ndn knock-out mice. Paternal Ndn allele-deficient mice were generated and maintained as described previously (Kuwako et al., 2005). Heterozygous male mice $\left(\mathrm{Ndn}^{+/-}\right)(>10$ generations in ICR background) were crossed with wild-type female mice $\left(\mathrm{Ndn}^{+/+}\right)$to obtain mutant mice. Genotypes of all mice used were analyzed by PCR for mutated $N d n$ locus. Experiments using gene-targeted mice were approved by the Recombinant DNA and Animal Experiment Committees of the Institute for Pro- 
A

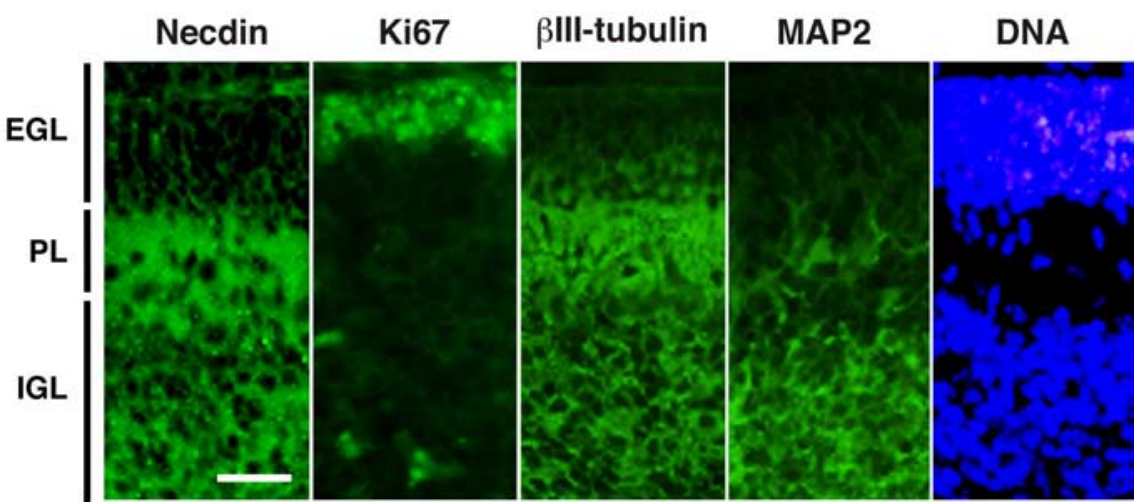

B
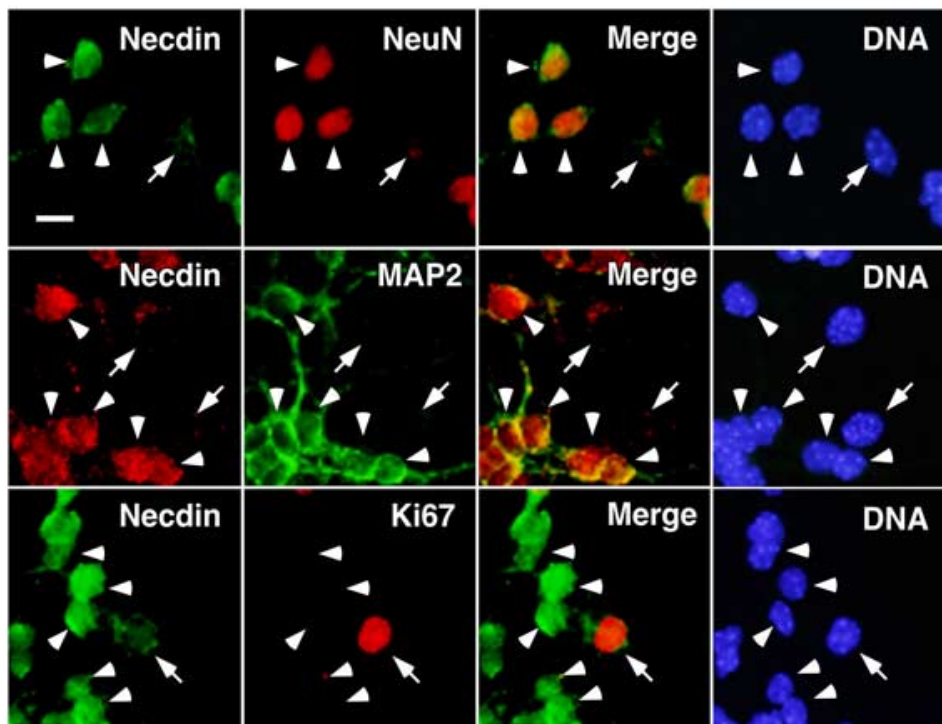

Figure 1. Necdin is expressed in CGNs. $\boldsymbol{A}$, Fluorescence immunohistochemistry. Frozen sections of P6 mouse cerebellum were immunostained for necdin, Ki67, $\beta$ III-tubulin, and MAP2. Chromosomal DNA was stained with Hoechst 33342. PL, Purkinje cell layer. $\boldsymbol{B}$, Fluorescence immunocytochemistry. Primary CGNs were prepared from mouse cerebellum at P6, cultured in the medium containing $25 \mathrm{~mm} \mathrm{KCl}$ for $48 \mathrm{~h}$, fixed, and double stained for necdin and NeuN, MAP2, or Ki67. Arrowheads point to CGNs, and arrows point to CGN progenitors or non-neuronal cells. Scale bars: $A, 50 \mu \mathrm{m} ; \boldsymbol{B}, 20 \mu \mathrm{m}$.

tein Research, Osaka University, and performed in accordance with institutional guidelines and regulations.

Reverse transcription-PCR. Total RNA was extracted with Trizol reagent (Invitrogen), and cDNA was synthesized from total RNA $(1.5 \mu \mathrm{g})$ using Moloney murine leukemia virus reverse transcriptase (Invitrogen). Aliquots of cDNA were used as templates for PCR (5 and 1\% for semiquantification and real-time quantification, respectively). Primers used for PCR are as follows: necdin (forward, $5^{\prime}$-aggacctgagcgacctaac- $3^{\prime}$; reverse, $5^{\prime}$-tgctgcaggattttagggtcaac- $3^{\prime}$ ), $c d c 2$ (forward, $5^{\prime}$-gtcaagaacctggacgagaa- $3^{\prime}$; reverse, $5^{\prime}$-gagccaacggtaaacaacac- $3^{\prime}$ ), E2F1 (forward, $5^{\prime}$-atggaagaggaccaactgtc- $3^{\prime}$; reverse, $5^{\prime}$-cctgaatccctaggcttctg- $3^{\prime}$ ), cdk2 (forward, $5^{\prime}$-cacagggcttgcacgtcact- $3^{\prime}$; reverse, $5^{\prime}$ - tgtctcctggcctgcatcac- $3^{\prime}$ ), E2F4 (forward, 5' -cttagccctctctacatgga- $3^{\prime}$; reverse, $5^{\prime}$-agactcctagctagacacag- $3^{\prime}$ ), cyclin A (forward, $5^{\prime}$-gttccttacccagtacttcc- $3^{\prime}$; reverse, $5^{\prime}$-agacaaggcttaagactctc- $3^{\prime}$ ), B-myb (forward, $5^{\prime}$-gagaagtacggaccgctgaa$3^{\prime}$; reverse, $5^{\prime}$-aggacatcagcttcccatct- $3^{\prime}$ ), and glyceraldehyde-3-phosphate dehydrogenase (GAPDH) (forward: 5'-gaatacggctacagcaacag-3', reverse: $5^{\prime}$-gcagcgaactttattgatggta- $\left.3^{\prime}\right)$. The sizes and amounts of PCR products were semiquantified by $1.5 \%$ agarose gel electrophoresis. Reverse transcription (RT)-PCR was quantified using a real-time cycler (LightCycler; Roche) with a program (Fast Start Program, LightCycler software version 3.5) and a reagent kit (FastStart DNA Master SYBR Green I kit; Roche).

In vitro kinase assay. CGNs were lysed in a buffer containing 50 mм Tris-HCl, pH 8.0, 150 $\mathrm{mm} \mathrm{NaCl}, 1 \%$ Nonidet P-40, 1 mм EDTA, and the Complete protease inhibitor mixture. The lysate $(300 \mu \mathrm{g})$ was incubated with anti-Cdc2 antibody [p34 (17); $4 \mu \mathrm{l}]$ at $4^{\circ} \mathrm{C}$ for $12 \mathrm{~h}$. Complexes bound to protein A-Sepharose were washed with the lysis buffer and then with the kinase buffer containing $50 \mathrm{~mm}$ Tris- $\mathrm{HCl}, \mathrm{pH}$ 7.6, and $10 \mathrm{~mm} \mathrm{MgCl}_{2}$. The beads were incubated with $2 \mu \mathrm{g}$ of histone $\mathrm{H} 1$ substrate (Millipore), $2 \mu \mathrm{l}$ of the inhibitor mixture (catalog \#20-116; Millipore), $2 \mu \mathrm{l}$ of $\mathrm{Mg}^{2+} /$ ATP mixture (Millipore), and $5 \mu \mathrm{Ci}$ of $\left[\gamma_{-}{ }^{32} \mathrm{P}\right] \mathrm{ATP}$ (Amersham Biosciences) in the kinase buffer at $30^{\circ} \mathrm{C}$ for $1 \mathrm{~h}$. After samples were separated by SDS-PAGE, phosphorylated histone $\mathrm{H} 1$ was detected by autoradiography and quantified with an image analyzer (BAS-2000; Fuji Film).

Immunoaffinity assay. Cerebellar lysates (2 $\mathrm{mg}$ ) prepared from P6 mice were applied to HiTrap $N$-hydroxysuccinimide-activated affinity columns (Amersham Biosciences) coupled with IgG fractions of anti-necdin antibody and preimmune serum. Bound proteins were eluted with $0.1 \mathrm{~m}$ glycine- $\mathrm{HCl}, \mathrm{pH} 2.5$. Fractions were precipitated with $10 \%$ trichloroacetic acid, rinsed with cold acetone, separated by $10 \%$ SDS-PAGE, and detected by Western blotting.

Statistical tests. Statistical significance was tested using an unpaired Student's $t$ test or oneway ANOVA, followed by the Tukey's post hoc test. A significance of $p<0.05$ was required for rejection of the null hypothesis.

\section{Results}

Necdin is abundantly expressed in mature CGNs

We first examined the expression pattern of necdin in the cerebellum in vivo by immunohistochemistry (Fig. 1A). In mouse cerebellum at $\mathrm{P} 6$, necdin immunoreactivity was intense in the Purkinje cell layer and the internal granule layer (IGL), in which $\beta$ III-tubulin and MAP2 immunoreactivities were also detected. The distribution pattern of necdin was similar to that of the early neuronal differentiation marker $\beta$ III-tubulin. On the other hand, necdin was moderately expressed in the external granule layer (EGL), in which proliferating and differentiating CGN progenitors are present. The cells immunopositive for the cell proliferation marker Ki67 were detected in the outermost layer of the EGL. Because differentiating CGNs migrate from the EGL into the IGL, it is likely that necdin is expressed in CGNs during their terminal differentiation.

We next examined the expression of necdin in primary CGNs in vitro (Fig. $1 \mathrm{~B}$ ). CGNs were prepared from the $\mathrm{P} 6$ cerebellum and cultured in the presence of $10 \%$ serum and a membrane depolarizing concentration $(25 \mathrm{~mm})$ of $\mathrm{KCl}$ for $48 \mathrm{~h}$. In these cultures, $>95 \%$ cells were positive for the postmitotic neuron markers NeuN and MAP2. Necdin-immunoreactive cells overlapped with NeuN- and MAP2-immunoreactive cells. Necdin immunoreactivity was distributed in both the nucleus and the cytosol. A very small number of cells in the primary cultures were 
positive for Ki67, and these cells contained low levels of necdin immunoreactivity. These findings indicate that necdin is expressed predominantly in differentiated CGNs but is also present, to a lesser extent, in undifferentiated or differentiating cells.

\section{Neuronal activity deprivation upregulates E2F1 and Cdc2 in CGNs}

A high concentration of $25 \mathrm{~mm} \mathrm{KCl}(\mathrm{HK})$ in the culture medium supports the survival of cultured CGNs, whereas a low concentration of $5 \mathrm{~mm} \mathrm{KCl} \mathrm{(LK)} \mathrm{induces} \mathrm{neuronal} \mathrm{apoptosis} \mathrm{(D'Mello} \mathrm{et}$ al., 1993). We cultured CGNs in the HK condition for $48 \mathrm{~h}$ and then in the LK condition for an additional $48 \mathrm{~h}$. Under these conditions, 25 and $38 \%$ of total cells had condensed or fragmented nuclei at 24 and $48 \mathrm{~h}$, respectively, as visualized by Hoechst 33342 staining (Fig. 2A). To confirm that CGNs undergo apoptosis in the LK condition, we performed TUNEL assay and immunocytochemistry for activated caspase-3, a principal apoptosis-inducing protease. In the LK condition, the numbers of TUNEL-positive CGNs were 2.0 and 3.8 times those of the HK controls at 24 and $48 \mathrm{~h}$, respectively (Fig. $2 \mathrm{~B}, \mathrm{C}$ ). Similarly, the numbers of CGNs containing activated caspase- 3 were 2.3 and 3.9 times those of the HK controls at 24 and $48 \mathrm{~h}$, respectively, in the LK condition (Fig. 2D,E). The different values of cell populations positive for these death markers may be attributable to the different sensitivities of the methods used.

Expression of E2F1 and Cdc2 increases during apoptosis of activity-deprived CGNs (O'Hare et al., 2000; Konishi et al., 2002). Thus, we examined the expression patterns of E2F1 and Cdc2 by Western blot analysis (Fig. $2 \mathrm{~F}$ ). The levels of E2F1 and Cdc2 clearly increased after $\mathrm{KCl}$ withdrawal, whereas those of necdin and E2F4, another target of necdin (Kobayashi et al., 2002), remained unchanged. We also analyzed the levels of the cell cyclerelated proteins cyclin A, cyclin B, and PCNA and found that these proteins remained constant in the LK condition. Because serum deprivation also induces apoptosis in CGNs (Miller and Johnson, 1996), we examined whether this treatment activates the E2F1-Cdc2 pathway in CGNs. When the FCS concentration in the culture medium was switched from 10 to $0.1 \%$ in the presence of $25 \mathrm{mM} \mathrm{KCl}$, neither E2F1 nor Cdc2 was upregulated (Fig. 2G), indicating that serum deprivation induces apoptosis of CGNs in a manner independent of E2F1 or Cdc2.

\section{Necdin represses $c d c 2$ gene transcription via E2F1}

To examine whether necdin represses E2F1-activated $c d c 2$ gene transcription, we first analyzed the effect of necdin on E2F1stimulated $c d c 2$ promoter activity using undifferentiated $\mathrm{P} 19 \mathrm{em}-$ bryonal carcinoma cells. E2F1 stimulated the $c d c 2$ promoter activity to approximately eight times the basal level, whereas coexpression of necdin repressed the E2F1-stimulated activity in a dose-dependent manner (Fig. 3A), suggesting that necdin suppresses the $c d c 2$ promoter activity through its interaction with E2F1. We next examined whether necdin is associated with the $c d c 2$ promoter via E2F1 by ChIP analysis (Fig. $3 B$ ). In P19 cells transfected with E2F1 and necdin cDNAs, E2F1 alone bound to the $c d c 2$ promoter, whereas necdin bound to the promoter only in the presence of coexpressed E2F1. This suggests that necdin suppresses E2F1-dependent $c d c 2$ transcriptional activation through its association with the promoter.

We next examined whether endogenous necdin is associated with the $c d c 2$ promoter in neurally differentiated P19 cells. Cdc2 expression was downregulated during the course of neuronal differentiation (Fig. 3C), whereas the expression levels of E2F1 and necdin were the highest in the retinoic acid-treated cells and post-
A

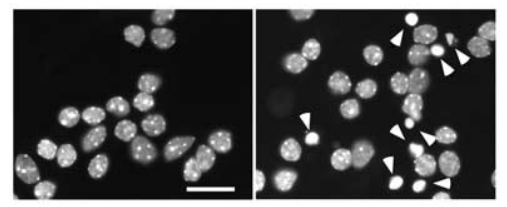

B

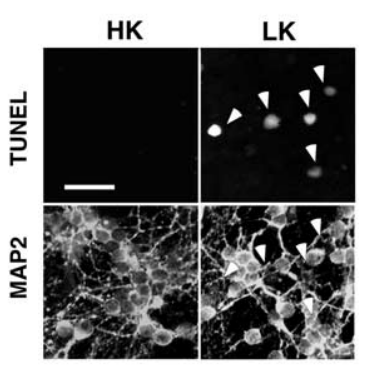

C

D

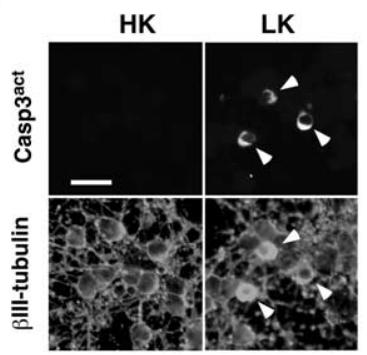

E

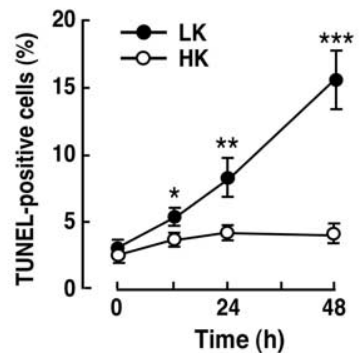

$\mathbf{F}$

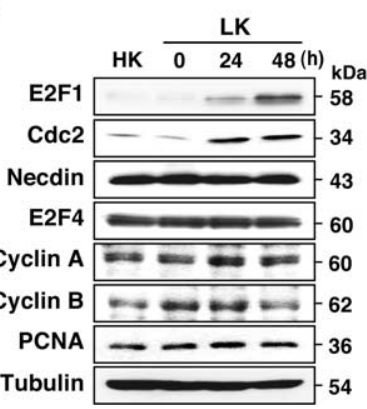

G
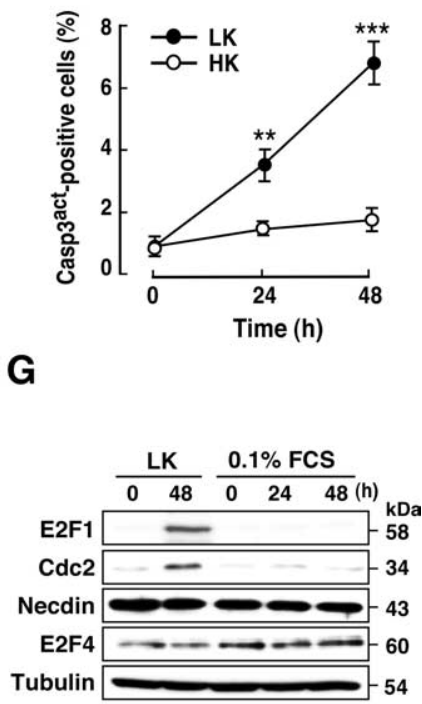

Figure 2. Apoptosis of CGNs is induced by activity deprivation. $\boldsymbol{A}$, Nuclear DNA staining. Primary CGNs were prepared from mouse cerebellum at P6, maintained in high $\mathrm{KCl}$-containing medium (HK; $25 \mathrm{~mm} \mathrm{KCl}$ plus 10\% FCS) for $48 \mathrm{~h}$, and then maintained in low KCl-containing medium (LK; 5 mm KCl plus 10\% FCS). Cells were stained with Hoechst 33342, and those with condensed or fragmented nuclei were observed (arrowheads). Images are shown at $0 \mathrm{~h}$ (left) and $24 \mathrm{~h}$ (right) in LK. $\boldsymbol{B}, \boldsymbol{C}$, TUNEL assay. $\boldsymbol{B}$, Primary CGNs were maintained in HK and LK for the indicated durations and double-stained for TUNEL and MAP2. C, TUNEL-positive cells among $>200$ MAP2-positive cells were counted $(n=3)$. D, $\boldsymbol{E}$, Immunocytochemistry for activated caspase-3.D, CGNs were cultured in HK and LK for the indicated durations and double stained for activated caspase-3 (Casp3 ${ }^{\text {act }}$ ) and $\beta I I I-$ tubulin. $\boldsymbol{E}$, Casp3 ${ }^{\text {act-positive cells among }>200 \beta} \beta$ IIItubulin-positive cells were counted $(n=3)$. Images at $24 \mathrm{~h}$ are shown in $\boldsymbol{B}$ and $\boldsymbol{D}$. Each point of the graphs $(\boldsymbol{C}, \boldsymbol{E})$ represents the mean \pm SEM. ${ }^{*} p<0.05 ;{ }^{* *} p<0.02 ;{ }^{* * *} p<0.01$. F, Western blot analysis. CGNs were cultured in LK for the indicated durations. Control CGNs were maintained in HK for $48 \mathrm{~h}$. The expression levels of E2F1, Cdc2, necdin, E2F4, cyclin A, cyclin B, PCNA, and tubulin in whole-cell lysates $(30 \mu \mathrm{g})$ were analyzed by Western blotting. $\mathbf{G}$, Western blot analysis. CGNs were cultured in LK or the medium containing $0.1 \% \mathrm{FCS}$ plus $25 \mathrm{~mm} \mathrm{KCl}(0.1 \%$ $\mathrm{FCS})$ for the indicated durations. Cell lysates $(30 \mu \mathrm{g})$ were analyzed by Western blotting. Scale bars: $A, B, D, 20 \mu \mathrm{m}$.

mitotic neurons, respectively. ChIP analysis revealed that E2F1 bound to the $c d c 2$ promoter at the three stages of neural differentiation, and its binding activity was the highest in retinoic acidtreated cells (Fig. 3D). Necdin was associated with the $c d c 2$ promoter in retinoic acid-treated cells and differentiated neurons, 
A

B

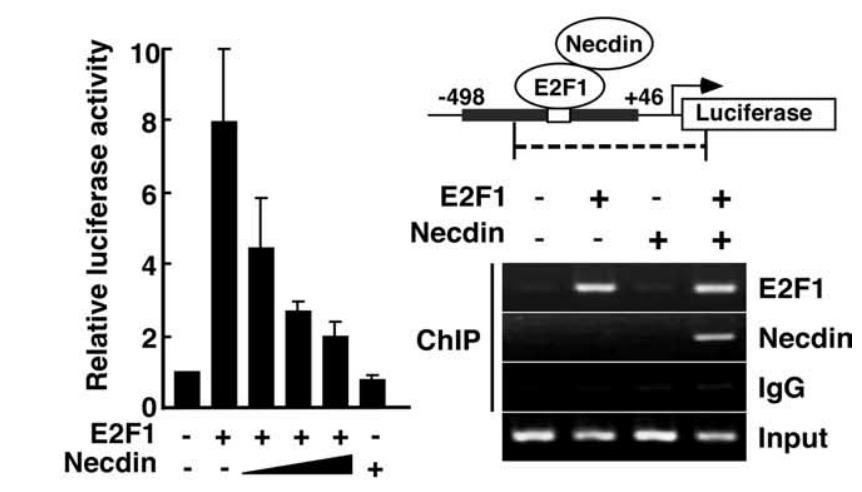

C

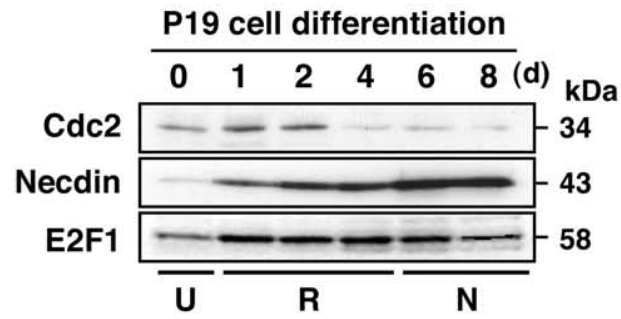

D

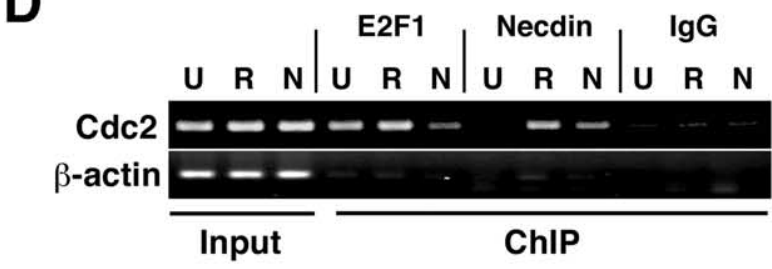

$\mathbf{E}$

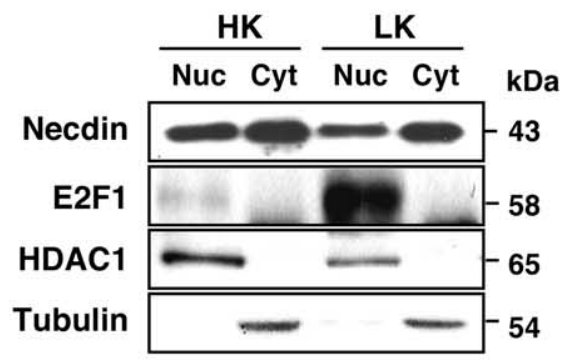

$\mathbf{F}$

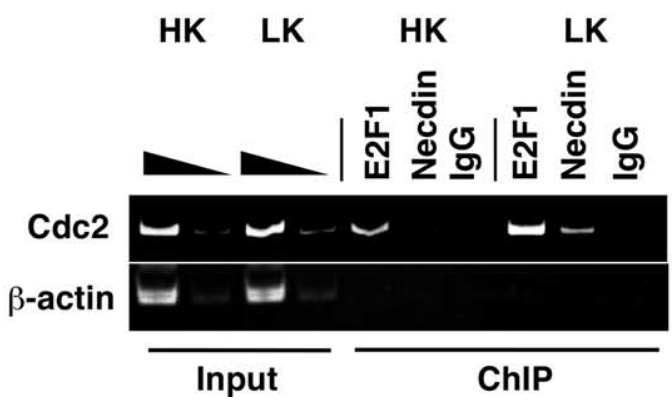

Figure 3. Necdin and E2F1 are colocalized at the cdc2 promoter in activity-deprived CGNs. $\boldsymbol{A}$, Luciferase reporter assay. P19 cells were transfected with mouse cdc2 promoter ( -498 / +46)-luciferase plasmid $(0.5 \mu \mathrm{g})$ in combination with CMV-E2F1 $(0.5 \mu \mathrm{g})$ and CMV-necdin $(0.5,1.0$, and $2.0 \mu \mathrm{g})$. After incubation for $24 \mathrm{~h}$, luciferase activity in cell lysates was measured with a luminometer (mean $\pm \mathrm{SEM} ; n=3$ ). $\boldsymbol{B}$, ChIP assay. P19 cells were transfected with mouse $c d c 2$ promoter-luciferase plasmid $(0.5 \mu \mathrm{g})$ in combination with CMV-E2F1 $(1.5 \mu \mathrm{g})$ and CMV-necdin $(2.0 \mu \mathrm{g})$. After incubation for $48 \mathrm{~h}$, the cells were cross-linked by formalin but not in undifferentiated cells in which necdin expression was very low. We also examined the association of necdin with promoters of other E2F-dependent genes such as DNA polymerase $\alpha$, cyclin A2, and PCNA by ChIP analysis but failed to detect the association of necdin with these promoters in neurally differentiated P19 cells (supplemental Fig. 1, available at www. jneurosci.org as supplemental material). These data together suggest that necdin is preferentially associated with the $c d c 2$ promoter via E2F1 during neuronal differentiation.

We then examined whether endogenous necdin and E2F1 are colocalized at the $c d c 2$ promoter in activity-deprived CGNs. In these cells, E2F1 was localized almost exclusively in the nucleus, whereas necdin was distributed in both the nucleus and the cytoplasm (Fig. 3E). ChIP analysis revealed that activity deprivation increased the amounts of E2F1 and necdin associated with the $c d c 2$ promoter (mean \pm SEM; $n=3 ; 1.9 \pm 0.4$ and $2.5 \pm 0.6$ times those of the HK controls, respectively) (Fig. $3 F$ ). These data suggest that endogenous necdin is associated with the $c d c 2$ promoter via $\mathrm{E} 2 \mathrm{~F} 1$ to repress $c d c 2$ gene transcription in activitydeprived CGNs.

\section{Necdin deficiency enhances the E2F1-Cdc2 pathway in activity-deprived CGNs}

We investigated whether endogenous necdin suppresses E2F1dependent $c d c 2$ gene expression in necdin-deficient CGNs. Primary CGNs were prepared from paternal necdin gene-deficient $\left(\mathrm{Ndn}^{+\mathrm{m} /-\mathrm{p}}\right)$ and wild-type $\left(\mathrm{Ndn}^{+\mathrm{m} /+\mathrm{p}}\right)$ littermates at P6. By Western blot analysis, necdin was undetected in CGNs prepared from $\mathrm{Ndn}^{+\mathrm{m} /-\mathrm{p}}$ mice. The $\mathrm{Cdc} 2$ levels in necdin-deficient CGNs were 1.8 and 1.4 times those in wild-type CGNs at 24 and $48 \mathrm{~h}$, respectively, in the LK condition (Fig. 4A,B). Similarly, the E2F1 levels in necdin-deficient CGNs were 1.7 and 1.5 times those in wild-type CGNs at 24 and $48 \mathrm{~h}$, respectively, in the LK condition. On the other hand, the levels of the cell cycle-related proteins cyclin A, cyclin B, and PCNA in necdin-deficient CGNs were unchanged (data not shown). These data suggest that endogenous necdin preferentially downregulates the expression of Cdc2 and $\mathrm{E} 2 \mathrm{~F} 1$

To rule out the possibility that necdin deficiency upregulates the expression of $\mathrm{Cdc} 2$ and $\mathrm{E} 2 \mathrm{~F} 1$ by enhancing $\mathrm{Rb}$ phosphorylation and degradation, we analyzed the phosphorylated and total $\mathrm{Rb}$ levels in necdin-deficient CGNs at 24 and $48 \mathrm{~h}$ after $\mathrm{KCl}$ withdrawal. Western blot analysis revealed that the levels of phosphorylated $\mathrm{Rb}$ moderately increased at $24 \mathrm{~h}$ and decreased at $48 \mathrm{~h}$

\footnotetext{
$\leftarrow$

treatment. The lysates $(0.5 \mathrm{mg})$ were immunoprecipitated with IgGs to mouse full-length E2F1 (MFE2F1), necdin, and control lgG. The plasmid-derived cdc2 promoter (dotted bar) was amplified by PCR using 1:30 of total immunoprecipitated DNA (ChIP) and 1:300 of total DNA for control (Input). C, Western blot analysis. Cell lysates $(30 \mu \mathrm{g}$ ) were prepared from undifferentiated, retinoic acid-treated, and neurally differentiated P19 cells at the times indicated and analyzed by Western blotting with antibodies to $\mathrm{Cdc}$, necdin, and E2F1 (C-20). D, ChIP assay. Formalin cross-linked cell lysates $(1 \mathrm{mg})$ of neurally differentiated P19 cells were immunoprecipitated as in $\boldsymbol{B}$. The $c d c 2$ and $\beta$-actin promoter sequences were amplified by PCR using input DNA (Input, 1:300) and total immunoprecipitated DNA (ChIP, 1:30). P19 cell lysates were prepared at 0,4 , and $8 \mathrm{~d}$ for undifferentiated, retinoic acid-treated, and neurally differentiated, respectively. $\boldsymbol{E}$, Western blot analysis. CGNs were maintained in HK and LK for $24 \mathrm{~h}$. Nuclear (Nuc) and cytoplasmic (Cyt) soluble fractions $(25 \mu \mathrm{g}$ ) were separated by SDS-PAGE and immunoblotted with antibodies against necdin, E2F1 (C-20), HDAC1 (nuclear marker), and tubulin (cytoplasmic marker). $\boldsymbol{F}$, ChIP assay. CGNs were maintained in HK and LK for $24 \mathrm{~h}$. Formalin cross-linked cell lysates $(1 \mathrm{mg})$ were immunoprecipitated as in $\boldsymbol{B}$. The $c d c 2$ and $\beta$-actin promoter sequences were amplified by PCR using input DNA (Input, 1:300 and 1:1500) and total immunoprecipitated DNA (ChIP, 1:30). CMV, Cytomegalovirus; $U$, undifferentiated; $R$, retinoic acid treated; $\mathrm{N}$, neurally differentiated.
} 
A

$\frac{\mathrm{Ndn}^{+\mathrm{m} /+\mathrm{p}}}{0 \frac{\mathrm{HK}}{2448} \frac{\mathrm{LK}}{2448}} \frac{\mathrm{Ndn}^{+\mathrm{m} / \mathrm{p}}}{\frac{\mathrm{HK}}{2448} \frac{\mathrm{LK}}{2448}}$

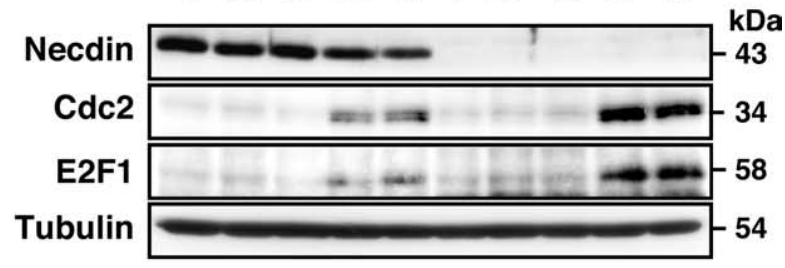

B
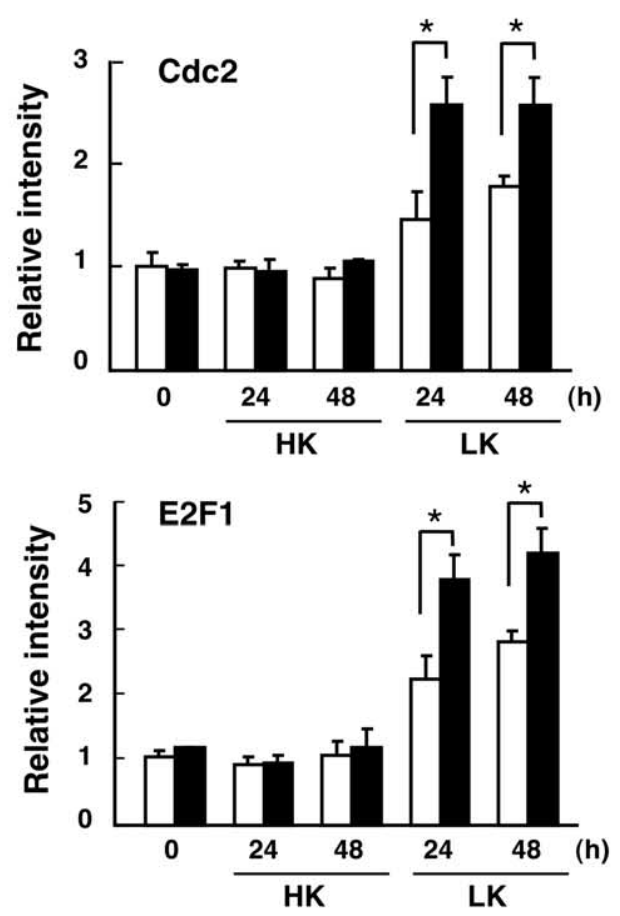

$\mathrm{Ndn}^{+\mathrm{m} / \mathrm{+p}}$ - Ndn $+\mathrm{m} /-\mathrm{p}$

C

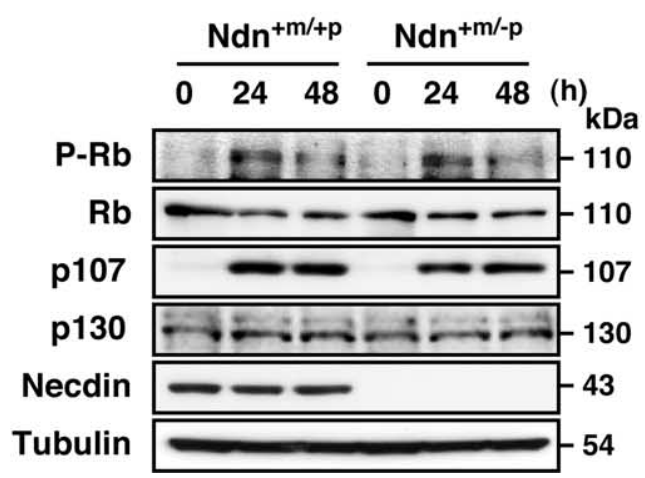

Figure 4. Necdin deficiency enhances the upregulation of $\mathrm{Cdc} 2$ and E2F1 proteins in activitydeprived CGNs. A, Western blot analysis. (GNs were prepared from wild-type $\left(\mathrm{Ndn}^{+\mathrm{m} /+\mathrm{p}}\right)$ and necdin-deficient $\left(\mathrm{Ndn}{ }^{+\mathrm{m} /-\mathrm{P}}\right.$ ) littermates at $\mathrm{P} 6$ and maintained in HK and LK for 24 and $48 \mathrm{~h}$. Proteins in cell lysates $(30 \mu \mathrm{g})$ were separated by $10 \%$ SDS-PAGE and detected with antibodies to necdin, Cdc2, E2F1, and tubulin. B, Quantification. Signal intensities of Cdc2 and E2F1 proteins were measured with an image analyzer. The intensities were normalized to those of tubulin (mean $\pm \mathrm{SEM} ; n=3$ ). ${ }^{*} p<0.05$. C, Western blot analysis. CGNs were maintained in LK for the indicated durations. Whole-cell lysates $(30 \mu \mathrm{g})$ were separated by $10 \%$ SDS-PAGE and immunoblotted for phospho-specific Rb (Ser795) (P-Rb), Rb, p107, and p130 as in A. Comparable data were obtained in three independent experiments. in both wild-type and necdin-deficient CGNs (Fig. 4C). However, there was no significant difference between wild-type and necdin-deficient CGNs in the levels of phosphorylated Rb (normalized with those of total $\mathrm{Rb}$ protein quantified by Western blotting) or the total $\mathrm{Rb}$ protein (normalized with the tubulin levels) at 24 and $48 \mathrm{~h}(n=3$; data not shown). These findings suggest that the enhanced upregulation of Cdc2 and E2F1 in necdin-deficient CGNs is not the result of augmented $\mathrm{Rb}$ phosphorylation or degradation. On the other hand, the p107 levels in CGNs were significantly increased at $24 \mathrm{~h}$ in the LK condition, whereas the p130 levels remained constant, consistent with the previous report (Padmanabhan et al., 1999). There were no appreciable differences in the levels of p107 and p130 at 24 and $48 \mathrm{~h}$ between wild-type and necdin-deficient CGNs.

We then examined the levels of $c d c 2$ and E2F1 transcripts by RT-PCR. Necdin mRNA was undetected in CGNs prepared from $\mathrm{Ndn}^{+\mathrm{m} /-\mathrm{p}}$ mice (Fig. 5A). In these necdin-deficient CGNs, the levels of $c d c 2$ and E2F1 mRNAs were clearly increased at 24 and $48 \mathrm{~h}$ in the LK condition. Real-time PCR analysis revealed that the cdc2 mRNA levels in necdin-deficient CGNs were 1.7 and 2.1 times those in wild-type controls at 24 and $48 \mathrm{~h}$, respectively, in the LK condition (Fig. 5B). In addition, the E2F1 mRNA levels in necdin-deficient CGNs were 1.5 and 1.9 times those of the controls at 24 and $48 \mathrm{~h}$, respectively. In contrast, there were no significant differences in the mRNA levels of $c d k 2$ and E2F4 (used as controls for $c d c 2$ and E2F1, respectively) between wild-type and necdin-deficient CGNs under these conditions. In addition, the mRNA levels of cyclin A and B-myb encoded in the E2F1responsive genes were unchanged in necdin-deficient CGNs. These results suggest that necdin deficiency specifically enhances the upregulated expression of both Cdc2 and E2F1 in activitydeprived CGNs.

\section{Cdc2-dependent apoptosis is augmented in necdin-deficient CGNs}

We next examined whether neuronal apoptosis is augmented in necdin-deficient CGNs. In the LK condition, apoptosis of necdin-deficient CGNs was significantly increased (1.4 and 1.2 times the wild-type controls at 24 and $48 \mathrm{~h}$, respectively) (Fig. $6 \mathrm{~A}$ ). The number of TUNEL-positive cells was also increased in necdin-deficient CGNs (Fig. 6B). We failed to detect the bromodeoxyuridine incorporation, an indication of DNA synthesis, into CGNs undergoing apoptosis (data not shown), consistent with the previous report (Konishi and Bonni, 2003). To examine whether Cdc2 accumulated in necdin-deficient CGNs is enzymatically active, in vitro $\mathrm{Cdc} 2$ kinase activity was measured using histone $\mathrm{H} 1$ as a substrate. The Cdc2 kinase activity of necdindeficient CGNs was significantly increased (1.6 times the wildtype control) in the LK condition (Fig. 6C,D). In addition, the amounts of immunoprecipitated $\mathrm{Cdc} 2$ protein correlated with Cdc2 kinase activities (Fig. $6 C$, top and second panels), suggesting that the $\mathrm{Cdc} 2$ protein accumulated in $\mathrm{Ndn}^{+\mathrm{m} /-\mathrm{p}}$ CGNs is enzymatically active. Roscovitine, a Cdc2 inhibitor, significantly diminished the augmented apoptosis of $\mathrm{Ndn}^{+\mathrm{m} /-\mathrm{p}}$ CGNs in the LK condition (Fig. $6 E$ ). In the presence of roscovitine, there was no significant difference in the number of TUNEL-positive cells between necdin-deficient and wild-type cultures in the LK condition. Similarly, the augmentation of LK-induced apoptosis at $24 \mathrm{~h}$ in necdin-deficient CGNs $\left(\mathrm{Ndn}^{+\mathrm{m} /+\mathrm{p}}, 23.7 \pm 1.1 \%\right.$; $\left.\mathrm{Ndn}^{+\mathrm{m} /-\mathrm{p}}, 33.7 \pm 1.5 \% ; p<0.002 ; n=3\right)$ was diminished in the presence of roscovitine $\left(\mathrm{Ndn}^{+\mathrm{m} /+\mathrm{p}}, 13.1 \pm 1.6 \% ; \mathrm{Ndn}^{+\mathrm{m} /-\mathrm{p}}\right.$, $11.8 \pm 1.8 \% ; p=0.63$ ) as analyzed by Hoechst 33342 staining. Although roscovitine also suppresses $\mathrm{Cdk} 2$ and $\mathrm{Cdk} 5$ activities, 

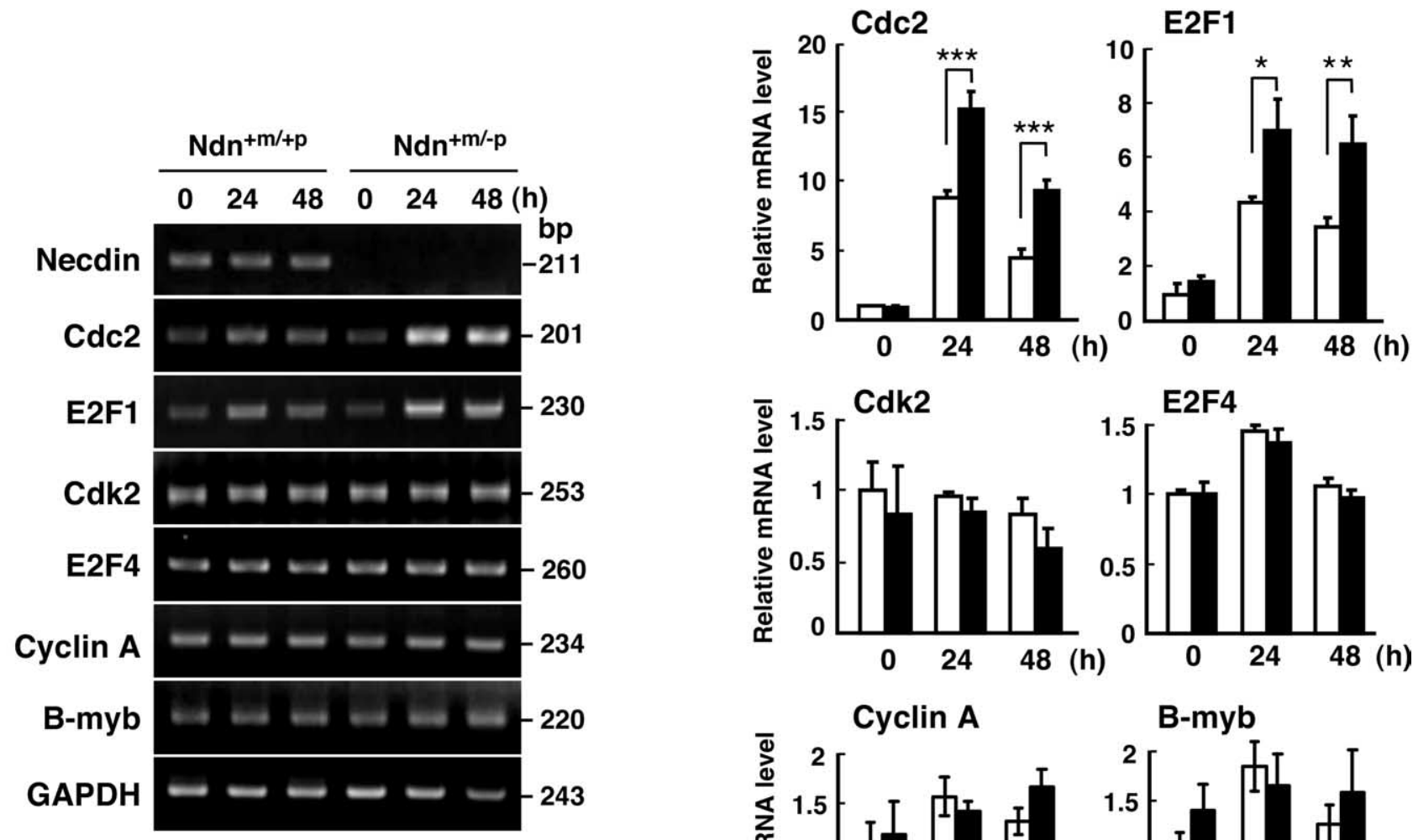

Cyclin A

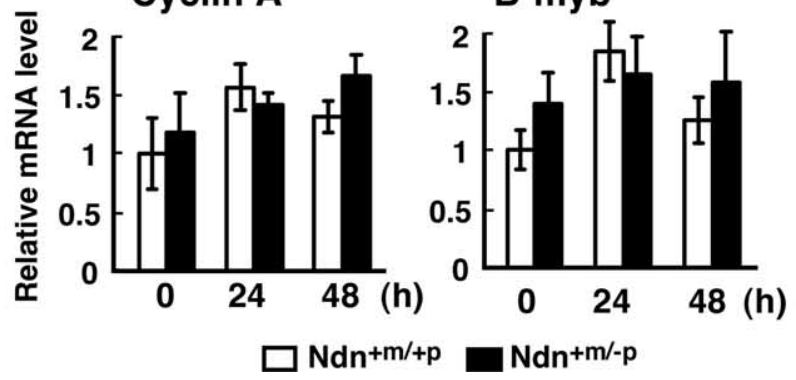

Figure 5. Necdin deficiency enhances the upregulation of $c d c 2$ and E2F1 mRNAs in activity-deprived CGNs. A, Semiquantitative RT-PCR. CGNs were prepared from Ndn ${ }^{+m /+p}$ and Ndn ${ }^{+m /-p}$ littermates at P6 and maintained in LK for the indicated durations. Total RNA (1.5 $\mu \mathrm{g})$ was reverse transcribed to CDNA, and $5 \%$ of total cDNA was used for PCR of specific CDNAs encoding necdin, Cdc2, E2F1, Cdk2, E2F4, cyclin A, B-myb, and GAPDH (30 cycles for B-myb; 28 cycles for Cdc2, E2F1, Cdk2, E2F4, and cyclin A; 26 cycles for necdin and GAPDH). PCR products were separated by 1.5\% agarose gel electrophoresis and stained with ethidium bromide (fragment sizes in base pairs). $\boldsymbol{B}$, Quantitative real-time PCR. CDNA (1\%) was amplified by real-time PCR using the primers as above. Melting curves were analyzed to confirm a single species per each PCR product. GAPDH cDNA was used as an internal standard to quantify the relative expression of each cDNA (mean \pm SEM; $n=$ 3). ${ }^{*} p<0.05 ;{ }^{* *} p<0.02 ;{ }^{* * *} p<0.01$.

the expression levels of $c d k 2$ and $c d k 5$ in CGNs were unchanged in the LK condition (Fig. 5 and data not shown). Thus, it is likely that augmented apoptosis of necdin-deficient CGNs is mediated by increased Cdc2 kinase activity. We also examined whether serum deprivation-stimulated apoptosis is enhanced in necdindeficient CGNs and found no significant difference in the number of apoptotic cells between necdin-deficient and wild-type cultures (data not shown). This suggests that endogenous necdin preferentially inhibits the activity deprivation-induced apoptosis of CGNs.

Both Cdc2 expression and apoptosis are increased in necdindeficient cerebellum in vivo

We investigated whether the number of apoptotic CGNs is also increased in the cerebellum in vivo of $\mathrm{Ndn}^{+\mathrm{m} /-\mathrm{p}}$ mice at P6. Immunoaffinity assay using anti-necdin antibody revealed that endogenous necdin interacted with E2F1 in the lysates prepared from the P6 cerebellum (Fig. 7A). We then examined whether the number of apoptotic CGNs is increased in the cerebellum in vivo of $\mathrm{Ndn}{ }^{+\mathrm{m} /-\mathrm{p}}$ mice at P6. Immunohistochemistry revealed that intensely Cdc2-immunoreactive cells were present in the EGL at this stage of development (Fig. $7 B$ ). On the other hand, a small number of cells in the IGL were also positive for Cdc2 in wildtype mice, consistent with the previous findings (Konishi et al., 2002). We counted the Cdc2-immunopositive cells among $>1800$ cells in the IGL of cerebellar folium III (examined 10 sections per pup). $\mathrm{Ndn}{ }^{+\mathrm{m} /-\mathrm{p}}$ mice had 1.7 times as many Cdc2positive cells as wild-type mice in the IGL $\left(\mathrm{Ndn}^{+\mathrm{m} /+\mathrm{p}}, 2.6 \pm\right.$ $0.4 \% ; \mathrm{Ndn}^{+\mathrm{m} /-\mathrm{p}}, 4.4 \pm 0.7 \%$; mean \pm SEM; $\left.n=4 ; p<0.05\right)$. These Cdc2-positive cells in the necdin-deficient cerebellum had a tendency to be localized in a deeper IGL area. We were unable to detect the difference in the number of Cdc2-expressing cells in the EGL in vivo between wild-type and $\mathrm{Ndn}^{+\mathrm{m} /-\mathrm{p}}$ mice because of the difficulty in quantifying Cdc2-positive cells in the EGL in vivo. Double immunostaining for $\mathrm{Cdc} 2$ and activated caspase- 3 revealed that only a small number of Cdc2-positive cells $(\sim 5 \%)$ in the IGL were positive for activated-caspase 3 (Fig. 7C), suggesting that caspase-dependent apoptosis occurs, at least in part, in the Cdc2-accumulating cells. Furthermore, we found that $\mathrm{Ndn}^{+\mathrm{m} /-\mathrm{p}}$ mice had 1.7 and 2.1 times as many TUNEL-positive cells as wild-type mice in the IGL and EGL, respectively (Fig. $7 D, E)$. These data suggest that endogenous necdin is involved in 
the suppression of apoptosis in both CGN progenitors and postmitotic CGNs.

\section{Discussion}

The present study has shown that endogenous necdin suppresses E2F1 expression to attenuate apoptosis of activity-deprived CGNs. $\mathrm{KCl}$ withdrawal rapidly activates cyclin-dependent kinases that subsequently induce phosphorylation and degradation of Rb in CGNs (Padmanabhan et al., 1999). In addition, E2F1 expression is upregulated during apoptosis of activitydeprived CGNs (O'Hare et al., 2000). In these situations, E2F1 efficiently activates the transcription of E2F-responsive genes with proapoptotic properties. On the other hand, necdin was strongly expressed in postmitotic CGNs (Fig. 1), and its levels in CGNs were unchanged during apoptosis (Fig. 2). In addition, activity deprivation-induced upregulation of E2F1 expression was significantly enhanced in necdin-deficient CGNs (Figs. 4, 5). This is because E2F1 gene transcription is upregulated by E2F1 itself through a positive regulatory loop (Johnson et al., 1994), which may be attenuated by endogenous necdin. On the other hand, there was little or no difference in $\mathrm{Rb}$ phosphorylation or degradation between wild-type and necdin-deficient CGNs under activity deprivation conditions (Fig. 4C). These findings together suggest that necdin suppresses aberrant E2F1 activation that is triggered by $\mathrm{Rb}$ phosphorylation during activity deprivation, but necdin directly inhibits E2F1 function without influencing the phosphorylation and degradation of $\mathrm{Rb}$.

It is generally difficult to demonstrate the interactions of E2F1 with its interactors in postmitotic neurons, in which endogenous E2F1 levels are nearly undetectable (Azuma-Hara et al., 1999). Therefore, we initially used gain-of-function analyses using transformed cells to study necdin-induced transcriptional repression of E2F-dependent promoters (Kobayashi et al., 2002; Kuwako et al., 2004). We also demonstrated that necdin suppresses E2F1-dependent apoptosis in differentiated neuroblastoma N1E-115 cells (Kobayashi et al., 2002; Kuwako et al., 2005). However, the physiological significance of the transcriptional repression of E2F1-dependent genes in neuronal apoptosis remained unclear in these gain-of-function studies. The present study has demonstrated that endogenous necdin is involved in the suppression of E2F1-dependent $c d c 2$ transcriptional activation and consequent apoptosis in primary necdin-deficient CGNs. We consider that such loss-of-function studies are essential to clarify the physiological significance of necdin in the regulation of neuronal apoptosis.

E2F1 activates the transcription of $c d c 2$, a typical cell cycleregulatory protein that is activated by cyclin $B$ in the $G_{2} / M$ phase of proliferating cells. During neuronal development, Cdc2 ex-
B
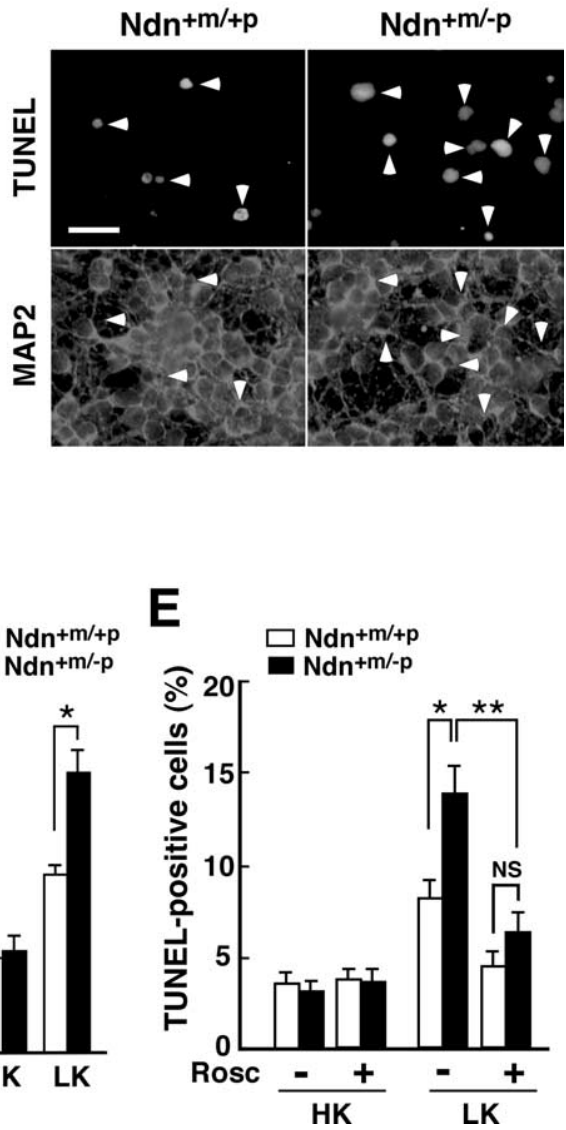

Figure 6. Cdc2 kinase activity and apoptosis are augmented in necdin-deficient CGNs.A, Quantification of apoptotic cells. CGNs were prepared from $\mathrm{Ndn}{ }^{+m /+p}$ and $\mathrm{Ndn}{ }^{+m /-p}$ littermates at P6. CGNs were maintained in HKand LK for the indicated durations and stained with Hoechst 33342 . Apoptotic cells with condensed or fragmented nuclei among $>200$ cells were counted (mean \pm neurons among $>200$ MAP2-positive cells are as follows: $\mathrm{Ndn}^{+\mathrm{m} /+\mathrm{p}}, 9.1 \pm 1.1 \%$; $\mathrm{Ndn}^{+\mathrm{m} /-\mathrm{p}}, 17.8 \pm 1.9 \%$ (mean $\pm \mathrm{SEM}$

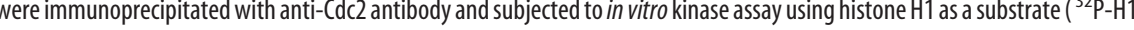
op panel) or immunoblotted with anti-Cdc2 antibody (second panel from the top). Lysates $(30 \mu \mathrm{g})$ were immunoblotted with

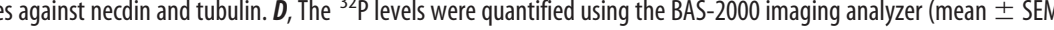
roscovitine (Rosc). TUNEL-positive cells among $>200 \mathrm{MAP2}$-positive cells were counted as in $\boldsymbol{B}$ (mean \pm SEM; $n=3$ ). ${ }^{*} p<0.02$; ${ }^{* *} p<0.01$. NS, Not significant $(p>0.05)$.

pression is high in proliferating neuronal precursors and dramatically downregulated after neuronal terminal differentiation (Hayes et al., 1991; Okano et al., 1993), suggesting that $c d c 2$ expression is completely suppressed in postmitotic neurons to stabilize their terminal differentiation. In activity-deprived CGNs, Cdc2 serves as a key cyclin-dependent kinase that induces apoptosis (Konishi and Bonni, 2003). Cdc2 induces apoptosis of CGNs through phosphorylation of $\mathrm{BH} 3$-only proapoptotic protein $\mathrm{BAD}$, in which serine 128 is phosphorylated by Cdc2 (Konishi et al., 2002). We demonstrated that endogenous necdin is associated with the $c d c 2$ promoter in activity-deprived CGNs (Fig. 3F) as well as in neurally differentiated P19 cells that contained high levels of endogenous necdin and E2F1 (Fig. 3C,D). In addition, necdin deficiency enhanced both Cdc2 expression (Figs. 4, 5) and the kinase activity (Fig. 6C,D) in activity-deprived CGNs, and the augmented apoptosis was suppressed by the Cdc2 inhibitor roscovitine (Fig. 6E). These findings suggest that endogenous necdin suppresses E2F1-dependent $c d c 2$ transcription 
A

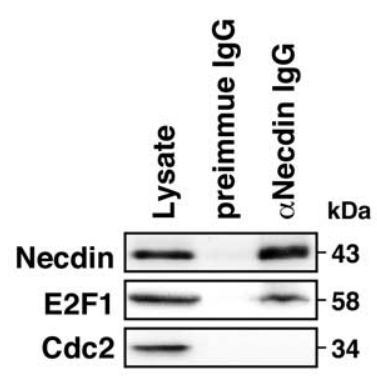

B

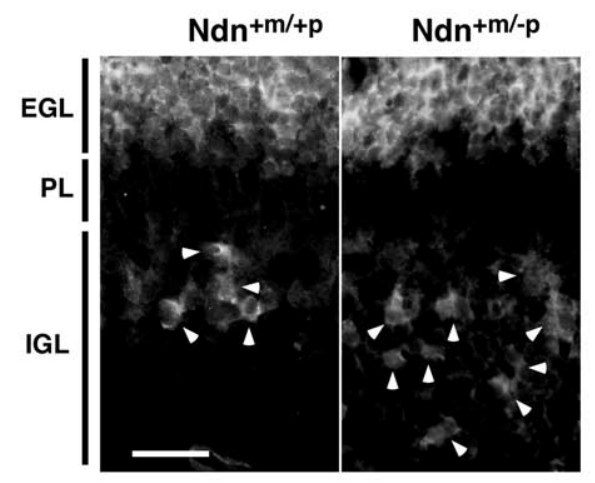

D

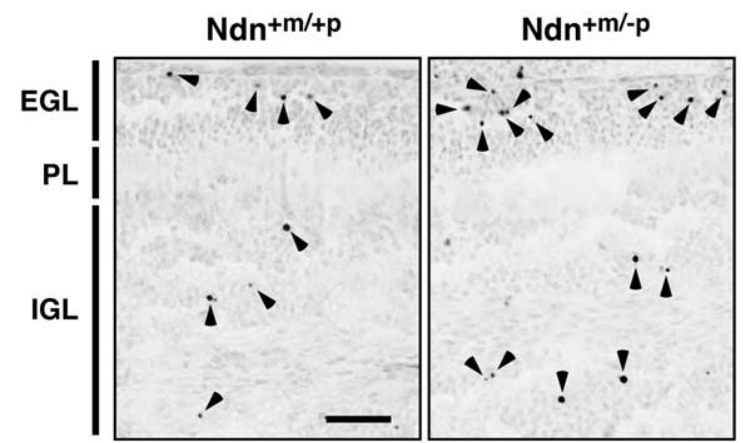

E

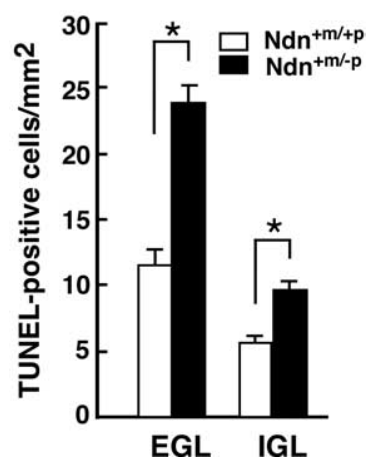

Figure 7. Necdin deficiency augments (dc2 expression and apoptosis in cerebellum in vivo. A, Cerebellar lysates ( $2 \mathrm{mg})$ of P6 mice were applied to affinity columns coupled with lgG fractions of anti-necdin antibody ( $\alpha$ Necdin $\lg G$ ) and preimmune serum (Preimmune lgG). Bound proteins were analyzed by Western blotting for necdin, E2F1, and Cdc2. Lysate, Tissue lysate (25 $\mu \mathrm{g})$. $\boldsymbol{B}$, Fluorescence immunohistochemistry. Paraffin-embedded sections of the cerebellum were prepared from $\mathrm{Ndn}{ }^{+\mathrm{m} /+\mathrm{p}}$ and $\mathrm{Ndn}^{+\mathrm{m} /-\mathrm{p}}$ mice at P6 and immunostained for $\mathrm{Cdc}$. Arrowheads point to $\mathrm{Cdc2}$-immunopositive cells in the IGL. $C$, Immunohistochemistry. Cells in the IGL were triply stained for (dc2, activated caspase-3 (Casp3 ${ }^{\text {act }}$ ), and chromosomal DNA (DNA). Note that a cell positive for both (dc 2 and activated caspase-3 has a condensed nucleus (arrowheads). D, E, TUNEL analysis. Frozen sections of the cerebellum from $\mathrm{Ndn}{ }^{+\mathrm{m} /+\mathrm{p}}$ and $\mathrm{Ndn}{ }^{+\mathrm{m} / \mathrm{p}}$ mice at $\mathrm{P} 6$ were stained for TUNEL. TUNEL-positive cells ( $\boldsymbol{D}$, arrowheads) were counted (sections examined: mean \pm SEM; $+m /+p, n=30 ;+m /-p, n=29)(\boldsymbol{E})$. Scale bars: $\boldsymbol{B}, 30 \mu \mathrm{m} ; \boldsymbol{C}, 10 \mu \mathrm{m} ; \boldsymbol{D}, 50 \mu \mathrm{m}$. ${ }^{*} p<0.001$.

and eventually reduces Cdc2 kinase activity to attenuate neuronal apoptosis.

Many cell cycle-regulatory proteins are upregulated during apoptosis of postmitotic neurons in a variety of developmental and pathological circumstances (Becker and Bonni, 2004; Greene et al., 2004; Herrup et al., 2004). Cyclin D1 is one of the best characterized cell cycle-regulatory proteins involved in neuronal apoptosis. Cyclin D1 mRNA is induced in cultured sympathetic neurons targeted to die after NGF withdrawal (Freeman et al., 1994). Cyclin D1/Cdk4 complex phosphorylates Rb family proteins and disrupts the Rb family protein-E2F complexes that suppress E2F-responsive proapoptotic genes (Greene et al., 2004). In CGNs, cyclin D1 remains constant, whereas most mRNAs markedly decrease after $\mathrm{KCl}$ deprivation, suggesting that cyclin D1 is relatively upregulated (Miller and Johnson, 1996). In addition, nuclear cyclin D1 levels are elevated along with enhanced cyclin D-associated kinase activity (Padmanabhan et al., 1999), which may also contribute to the activity deprivation-induced apoptosis of CGNs. On the other hand, Cdc2 expression is not upregulated in NGF-withdrawn sympathetic neurons (Freeman et al., 1994). These findings suggest that cell cycle proteins involved in neuronal apoptosis differ among neuronal types and apoptotic
C

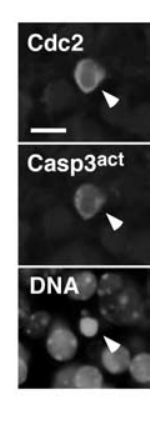

stimuli. Although necdin preferentially suppresses activity deprivation-induced apoptosis that is mediated by the E2F1Cdc2 pathway in CGNs, we infer that necdin also suppresses neuronal apoptosis evoked by neurotrophin withdrawal, which causes the de-repression of E2Fresponsive genes (Liu and Greene, 2001; Greene et al., 2004). Necdin is strongly expressed in peripheral sympathetic and sensory neurons that depend on NGF for their maturation and survival (Uetsuki et al., 1996; Takazaki et al., 2002; Kuwako et al., 2005). In addition, necdin, like Rb, interacts with both E2F1 and E2F4 (Taniura et al., 1998; Kobayashi et al., 2002). These findings suggest that necdin forms complexes with these E2F proteins and attenuates apoptosis induced by E2F-responsive proapoptotic genes in neurotrophinwithdrawn neurons.

The presence of Cdc2-accumulating cells in the IGL of the cerebellum in vivo suggests that Cdc2 expression is upregulated in postmitotic CGNs during normal development (Hayes et al., 1991; Konishi et al., 2002). We found that the populations of Cdc2-immunopositive and TUNEL-positive CGNs were significantly increased in the IGL in vivo of necdindeficient mice (Fig. 7). These findings suggest that $\mathrm{Cdc} 2$-mediated apoptosis of activity-deprived CGNs in vitro correlates with that of CGNs in vivo. Intriguingly, we also found that TUNEL-positive cells in the EGL were increased in necdindeficient cerebellum (Fig. $7 D, E$ ). We have reported previously that necdin is expressed in postmitotic neurons but not in proliferative progenitors in the neocortex (Uetsuki et al., 1996; Yoshikawa, 2000). On the other hand, the present study has shown that necdin was moderately expressed in the EGL in vivo at P6 (Fig. 1A) and primary cells immunopositive for the proliferative cell marker Ki67 (Fig. $1 B$, bottom panels), indicating that necdin is expressed not only in mature postmitotic neurons but also in undifferentiated cells such as neuronal progenitors and nascent neurons during postnatal differentiation of CGNs. It has been reported that newly generated CGNs in the EGL undergo apoptosis to appropriate neuronal populations during the first 2 weeks of postnatal development (Wood et al., 1993). These findings suggest that the augmented apoptosis in the EGL in vivo of necdin-deficient cerebellum is attributable, at least in part, to the deregulation of the E2F1-Cdc2 system at early stages of CGN differentiation. Necdin interacts with various proteins involved in neuronal apoptosis such as $\mathrm{p} 53$, hypoxia-inducible factor- $1 \alpha$, and the neurotrophin receptor p75 (Taniura et al., 1999; Tcherpakov et al., 2002; Kuwako et al., 2004; Moon et al., 2005). Thus, we cannot rule out the possibility that these necdin-interacting molecules other than E2F1-related cell cycle proteins are responsible for the enhanced apoptosis in vivo in the EGL of necdin-deficient mice. Additional studies are needed to elucidate the detailed mechanisms of cell death in cerebellar EGL of necdin-deficient mice. 
Necdin is a member of the large MAGE (melanoma antigen) family proteins, which contain the MAGE homology domain. Thus, it is likely that MAGE family proteins with functional similarities to necdin compensate the abnormalities caused by necdin deficiency. Among these necdin-related MAGE proteins, necdin-like 2 (also known as MAGE-G1) is a strong candidate that compensates the deficiency because it interacts with E2F1 and suppresses E2F1-dependent apoptosis (Kuwako et al., 2004). However, little is known about the expression and function of necdin-related MAGE proteins in specific neurons. Therefore, the compensatory function of MAGE family proteins in necdindeficient neurons remains to be elucidated.

Necdin targets many regulatory proteins that control neuronal life-and-death and differentiation (Taniura et al., 1998, 1999; Kobayashi et al., 2002; Tcherpakov et al., 2002; Kuwajima et al., 2004, 2006; Kuwako et al., 2004, 2005; Moon et al., 2005). Thus, necdin might serve as a hub protein in the network of proteinprotein interactions to promote and stabilize neuronal terminal differentiation. PWS is characterized by hyperphagia, short stature, and hypogonadism, which are believed to result from hypothalamic deficiency. However, individuals with PWS display a wide variety of neurological and behavioral abnormalities that indicate extensive defects of neuronal development throughout the peripheral and central nervous systems. Intriguingly, a PWS case with cerebellar hemisphere hypoplasia has recently been reported (Titomanlio et al., 2006). Thus, the present findings may promote a better understanding of molecular mechanisms underlying brain abnormalities seen in this neurodevelopmental disorder. Additional information about the role of necdin in E2Fmediated apoptosis will provide valuable insights into neuronal death in various developmental and pathological circumstances.

\section{References}

Aizawa T, Maruyama K, Kondo H, Yoshikawa K (1992) Expression of necdin, an embryonal carcinoma-derived nuclear protein, in developing mouse brain. Brain Res Dev Brain Res 68:265-274.

Azuma-Hara M, Taniura H, Uetsuki T, Niinobe M, Yoshikawa K (1999) Regulation and deregulation of E2F1 in postmitotic neurons differentiated from embryonal carcinoma P19 cells. Exp Cell Res 251:442-451.

Becker EB, Bonni A (2004) Cell cycle regulation of neuronal apoptosis in development and disease. Prog Neurobiol 72:1-25.

D’Mello SR, Galli C, Ciotti T, Calissano P (1993) Induction of apoptosis in cerebellar granule neurons by low potassium: inhibition of death by insulin-like growth factor I and cAMP. Proc Natl Acad Sci USA 90:10989-10993.

Ferguson KL, Slack RS (2001) The Rb pathway in neurogenesis. NeuroReport 12:A55-A62.

Freeman RS, Estus S, Johnson Jr EM (1994) Analysis of cell cycle-related gene expression in postmitotic neurons: selective induction of cyclin D1 during programmed cell death. Neuron 12:343-355.

Gerard M, Hernandez L, Wevrick R, Stewart CL (1999) Disruption of the mouse necdin gene results in early post-natal lethality. Nat Genet 23:199-202.

Greene LA, Biswas SC, Liu DX (2004) Cell cycle molecules and vertebrate neuron death: E2F at the hub. Cell Death Differ 11:49-60.

Hayashi Y, Matsuyama K, Takagi K, Sugiura H, Yoshikawa K (1995) Arrest of cell growth by necdin, a nuclear protein expressed in postmitotic neurons. Biochem Biophys Res Commun 213:317-324.

Hayes TE, Valtz NL, McKay RD (1991) Downregulation of CDC2 upon terminal differentiation of neurons. New Biol 3:259-269.

Herrup K, Neve R, Ackerman SL, Copani A (2004) Divide and die: cell cycle events as triggers of nerve cell death. J Neurosci 24:9232-9239.

Hou ST, Callaghan D, Fournier MC, Hill I, Kang L, Massie B, Morley P, Murray C, Rasquinha I, Slack R, MacManus JP (2000) The transcription factor E2F1 modulates apoptosis of neurons. J Neurochem 75:91-100.

Hou ST, Xie X, Baggley A, Park DS, Chen G, Walker T (2002) Activation of the $\mathrm{Rb} / \mathrm{E} 2 \mathrm{~F} 1$ pathway by the nonproliferative p38 MAPK during Fas
(APO1/CD95)-mediated neuronal apoptosis. J Biol Chem 277:48764-48770.

Ichikawa D, Tabuchi A, Taoka A, Tsuchiya T, Tsuda M (1998) Attenuation of cell death mediated by membrane depolarization different from that by exogenous BDNF in cultured mouse cerebellar granule cells. Brain Res Mol Brain Res 56:218-226.

Jacks T, Fazeli A, Schmitt EM, Bronson RT, Goodell MA, Weinberg RA (1992) Effects of an Rb mutation in the mouse. Nature 359:295-300.

Jay P, Rougeulle C, Massacrier A, Moncla A, Mattei MG, Malzac P, Roeckel N, Taviaux S, Lefranc JL, Cau P, Berta P, Lalande M, Muscatelli F (1997) The human necdin gene, NDN, is maternally imprinted and located in the Prader-Willi syndrome chromosomal region. Nat Genet 17:357-361.

Johnson DG, Ohtani K, Nevins JR (1994) Autoregulatory control of E2F1 expression in response to positive and negative regulators of cell cycle progression. Genes Dev 8:1514-1525.

Kobayashi M, Taniura H, Yoshikawa K (2002) Ectopic expression of necdin induces differentiation of mouse neuroblastoma cells. J Biol Chem 277:42128-42135.

Konishi Y, Bonni A (2003) The E2F-Cdc2 cell-cycle pathway specifically mediates activity deprivation-induced apoptosis of postmitotic neurons. J Neurosci 23:1649-1658.

Konishi Y, Lehtinen M, Donovan N, Bonni A (2002) Cdc2 phosphorylation of BAD links the cell cycle to the cell death machinery. Mol Cell 9:1005-1016.

Kuwajima T, Taniura H, Nishimura I, Yoshikawa K (2004) Necdin interacts with the Msx2 homeodomain protein via MAGE-D1 to promote myogenic differentiation of C2C12 cells. J Biol Chem 279:40484-40493.

Kuwajima T, Nishimura I, Yoshikawa K (2006) Necdin promotes GABAergic neuron differentiation in cooperation with Dlx homeodomain proteins. J Neurosci 26:5383-5392.

Kuwako K, Taniura H, Yoshikawa K (2004) Necdin-related MAGE proteins differentially interact with the E2F1 transcription factor and the p75 neurotrophin receptor. J Biol Chem 279:1703-1712.

Kuwako K, Hosokawa A, Nishimura I, Uetsuki T, Yamada M, Nada S, Okada M, Yoshikawa K (2005) Disruption of the paternal necdin gene diminishes TrkA signaling for sensory neuron survival. J Neurosci 25:7090-7099.

Lee EY, Hu N, Yuan SS, Cox LA, Bradley A, Lee WH, Herrup K (1994) Dual roles of the retinoblastoma protein in cell cycle regulation and neuron differentiation. Genes Dev 8:2008-2021.

Lee S, Walker CL, Karten B, Kuny SL, Tennese AA, O’Neill MA, Wevrick R (2005) Essential role for the Prader-Willi syndrome protein necdin in axonal outgrowth. Hum Mol Genet 14:627-637.

Liu DX, Greene LA (2001) Regulation of neuronal survival and death by E2F-dependent gene repression and derepression. Neuron 32:425-438.

Luo RX, Postigo AA, Dean DC (1998) Rb interacts with histone deacetylase to repress transcription. Cell 92:463-473.

MacDonald HR, Wevrick R (1997) The necdin gene is deleted in PraderWilli syndrome and is imprinted in human and mouse. Hum Mol Genet 6:1873-1878.

Maruyama K, Usami M, Aizawa T, Yoshikawa K (1991) A novel brainspecific mRNA encoding nuclear protein (necdin) expressed in neurally differentiated embryonal carcinoma cells. Biochem Biophys Res Commun 178:291-296.

McBurney MW, Reuhl KR, Ally AI, Nasipuri S, Bell JC, Craig J (1988) Differentiation and maturation of embryonal carcinoma-derived neurons in cell culture. J Neurosci 8:1063-1073.

Miller TM, Johnson JrEM (1996) Metabolic and genetic analyses of apoptosis in potassium/serum-deprived rat cerebellar granule cells. J Neurosci 16:7487-7495.

Moon HE, Ahn MY, Park JA, Min KJ, Kwon YW, Kim KW (2005) Negative regulation of hypoxia inducible factor-1alpha by necdin. FEBS Lett 579:3797-3801.

Muscatelli F, Abrous DN, Massacrier A, Boccaccio I, Moal ML, Cau P, Cremer H (2000) Disruption of the mouse Necdin gene results in hypothalamic and behavioral alterations reminiscent of the human Prader-Willi syndrome. Hum Mol Genet 9:3101-3110.

Nakada Y, Taniura H, Uetsuki T, Inazawa J, Yoshikawa K (1998) The human chromosomal gene for necdin, a neuronal growth suppressor, in the Prader-Willi syndrome deletion region. Gene 213:65-72.

Nevins JR (2001) The Rb/E2F pathway and cancer. Hum Mol Genet 10:699-703. 
Niinobe M, Koyama K, Yoshikawa K (2000) Cellular and subcellular localization of necdin in fetal and adult mouse brain. Dev Neurosci 22:310-319.

Nishimura I, Uetsuki T, Dani SU, Ohsawa Y, Saito I, Okamura H, Uchiyama Y, Yoshikawa K (1998) Degeneration in vivo of rat hippocampal neurons by wild-type Alzheimer amyloid precursor protein overexpressed by adenovirus-mediated gene transfer. J Neurosci 18:2387-2398.

Nishimura I, Uetsuki T, Kuwako K, Hara T, Kawakami T, Aimoto S, Yoshikawa K (2002) Cell death induced by a caspase-cleaved transmembrane fragment of the Alzheimer amyloid precursor protein. Cell Death Differ 9:199-208.

O’Hare MJ, Hou ST, Morris EJ, Cregan SP, Xu Q, Slack RS, Park DS (2000) Induction and modulation of cerebellar granule neuron death by E2F-1. J Biol Chem 275:25358-25364.

Okano HJ, Pfaff DW, Gibbs RB (1993) RB and Cdc2 expression in brain: correlations with $3 \mathrm{H}$-thymidine incorporation and neurogenesis. J Neurosci 13:2930-2938.

Padmanabhan J, Park DS, Greene LA, Shelanski ML (1999) Role of cell cycle regulatory proteins in cerebellar granule neuron apoptosis. J Neurosci 19:8747-8756.

Pagliardini S, Ren J, Wevrick R, Greer JJ (2005) Developmental abnormalities of neuronal structure and function in prenatal mice lacking the Prader-Willi syndrome gene necdin. Am J Pathol 167:175-191.

Park DS, Morris EJ, Bremner R, Keramaris E, Padmanabhan J, Rosenbaum M, Shelanski ML, Geller HM, Greene LA (2000) Involvement of retinoblastoma family members and E2F/DP complexes in the death of neurons evoked by DNA damage. J Neurosci 20:3104-3114.

Ren J, Lee S, Pagliardini S, Gerard M, Stewart CL, Greer JJ, Wevrick R (2003) Absence of Ndn, encoding the Prader-Willi syndrome-deleted gene necdin, results in congenital deficiency of central respiratory drive in neonatal mice. J Neurosci 23:1569-1573.

Sutcliffe JS, Han M, Christian SL, Ledbetter DH (1997) Neuronallyexpressed necdin gene: an imprinted candidate gene in Prader-Willi syndrome. Lancet 350:1520-1521.
Takazaki R, Nishimura I, Yoshikawa K (2002) Necdin is required for terminal differentiation and survival of primary dorsal root ganglion neurons. Exp Cell Res 277:220-232.

Taniguchi N, Taniura H, Niinobe M, Takayama C, Tominaga-Yoshino K, Ogura A, Yoshikawa K (2000) The postmitotic growth suppressor necdin interacts with a calcium-binding protein (NEFA) in neuronal cytoplasm. J Biol Chem 275:31674-31681.

Taniura H, Taniguchi N, Hara M, Yoshikawa K (1998) Necdin, a postmitotic neuron-specific growth suppressor, interacts with viral transforming proteins and cellular transcription factor E2F1. J Biol Chem 273:720-728.

Taniura H, Matsumoto K, Yoshikawa K (1999) Physical and functional interactions of neuronal growth suppressor necdin with p53. J Biol Chem 274:16242-16248.

Tcherpakov M, Bronfman FC, Conticello SG, Vaskovsky A, Levy Z, Niinobe M, Yoshikawa K, Arenas E, Fainzilber M (2002) The p75 neurotrophin receptor interacts with multiple MAGE proteins. J Biol Chem 277:49101-49104.

Titomanlio L, De Brasi D, Romano A, Genesio R, Diano AA, Del Giudice E (2006) Partial cerebellar hypoplasia in a patient with Prader-Willi syndrome. Acta Paediatr 95:861-863.

Uetsuki T, Takagi K, Sugiura H, Yoshikawa K (1996) Structure and expression of the mouse necdin gene. Identification of a postmitotic neuronrestrictive core promoter. J Biol Chem 271:918-924.

Uetsuki T, Takemoto K, Nishimura I, Okamoto M, Niinobe M, Momoi T, Miura M, Yoshikawa K (1999) Activation of neuronal caspase-3 by intracellular accumulation of wild-type Alzheimer amyloid precursor protein. J Neurosci 19:6955-6964.

Weinberg RA (1995) The retinoblastoma protein and cell cycle control. Cell 81:323-330.

Wood KA, Dipasquale B, Youle RJ (1993) In situ labeling of granule cells for apoptosis-associated DNA fragmentation reveals different mechanisms of cell loss in developing cerebellum. Neuron 11:621-632.

Yoshikawa K (2000) Cell cycle regulators in neural stem cells and postmitotic neurons. Neurosci Res 37:1-14. 